\title{
Understanding the Synergic Corrosion Issues with Regard to the Water Treatment Station
}

\author{
Renata Włodarczyk ${ }^{1 *}$, Klaudiusz Majek $^{2}$ \\ 1 Institute of Advanced Energy Technologies, Faculty of Infrastructure and Environment, Czestochowa \\ University of Technology, ul. Brzeznicka 60A, 42-200 Czestochowa, Poland \\ 2 Comprehensive Implementation of Municipal and Industrial Investments - Instal Warszawa S.A. Capital \\ Group Seen Holding Sp. z o.o., ul. Siennicka 29, 04-394 Warszawa \\ * Corresponding author's e-mail: rwlodarczyk@is.pcz.czest.pl
}

\begin{abstract}
The paper presents the examples of damage of elements caused by incorrect assessment of pipeline work conditions. The presented damage cases resulted in the need to replace pipelines. This work is an analysis pertaining to the impact of chemical and microbiological synergy of corrosion on stainless steel pipelines. The paper investigates the corrosion mechanisms that may occur under normal operating conditions at each water treatment station, and the methods of counteracting the corrosion were indicated. The analysis of the corrosion mechanisms was formulated taking into account the design stage, - the correctness of the steel grade choice by the designer, the stage of implementation - the most common implementation errors, and the operational stage - optimization of the technological system work and the effects of the introduced changes. The analysis was carried out at a water treatment plant in Poland with a maximum flow of $20,000 \mathrm{~m}^{3}$ a day ${ }^{-1}$, which draws raw water from deep water intakes and from a surface intake. The treatment technology includes an aeration system (aeration) and a two-stage treatment process using sand and carbon filters. The disinfection process and prophylaxis in the water treatment plant is based on the use of chlorine gas.
\end{abstract}

Keywords: chlorination, corrosion microbiology, pitting corrosion, synergy effect, water treatment station

\section{INTRODUCTION}

The requirements to maintain water parameters for consumption and to reduce water production costs, enforce the use of additional products to speed up the treatment process [GE Power \& Water., 1997-2012]. Shortening the treatment process by applying the treatment technology with simultaneous chemical support, results in faster wear of pipelines and devices. During the operation of the installation, there are frequent changes in the conditions, which leads to mechanical and chemical changes in the materials [Hilbert et al. 2010]. In order to effectively counteract any degradation processes, each type of pipeline or device should be tested in order to understand the role of particular factors and their impact on the corrosion processes in a given environment.
Degradation of materials causes changes in the tightness and durability of pipelines. The concept of corrosion, in a broad sense, means the destruction of material as a result of its interaction with the surrounding environment [Suslov, 2001]. This phenomenon involves undesirable processes of material destruction as a result of chemical or physicochemical environmental impacts that reduce the usable properties of pipelines. The operation of the environment causes the material to change from a metallic to an ionic state.

\section{Corrosion processes classification}

The corrosive destruction processes are generally very complex and overlap. For this reason, there are many possibilities to classify this phenomenon. The classification of corrosive damage 
can be made on the basis of the nature of changes that the metal surface undergoes or on the basis of the physical and mechanical changes of metal and alloy properties [Suslov, 2001]. In general, the mechanisms of corrosive processes are classified as resulting from the chemical, electrochemical, mechanical factors (erosion, cavitation) and the microbiological factors.

The chemical corrosion is the destruction of metals and alloys as a result of oxidation reactions. The material degradation process runs dry without the use of electrolyte [Cutler, 2003]. In the case of electrochemical corrosion, two processes occur simultaneously: oxidation, i.e. dissolution of metals and reduction, i.e. hydrogen evolution, oxygen reduction, metal separation, etc. Depending on the environment in which the material is used, a distinction is made between: corrosion in a moist environment (in sea water, atmosphere, corrosion in soil), in molten salts and gas corrosion (low temperature and high temperature).

An important criterion for the division of corrosive damage is their nature and course. In this case, it is referred to as general corrosion, which covers the entire surface of the metal and local corrosion, which causes the destruction of only certain places on the surface of metal elements, leaving other intact areas [Avery et al., 1999; Mameng et al. 2011]. General corrosion can occur as uniform corrosion - it spreads on the metal surface at the same rate, causing the same loss of wall thickness. The local corrosion is another type, involving local areas characterized by the selective destruction of certain alloy constituents. Its measure is the size and density of the distribution of corrosive foci. Even corrosion is the least dangerous type of corrosion, provided that the rate of corrosive dissolution of the metal does not exceed the standards specified in the scale of resistance of metals. If the thickness of the metal is sufficient, even corrosion has a small effect on reducing the mechanical strength of the structure (compression, stretching). This type of corrosion is dangerous when the pipeline components involve bending or twisting, because the layers subjected to the heaviest loads are destroyed. It occurs in critical elements: weld spots, pipeline diameter reduction, knees and tees. Localized corrosion occurs in many varieties, showing signs of both gas and electrochemical corrosion [Cutler, 2003]. It may have a different degree of unevenness. Localized corrosion is more dangerous than even corrosion, because it strongly affects the mechanical properties of the metal, mainly in the structures the strength of which depends on the strength of the weakest cross-section. The temperature rise is a factor favoring the rate of formation of local corrosion.

Pitting corrosion is a dangerous phenomenon occurring in installations (see Figure 1.). The corrosion points, so-called pits, occur in the form of local metal losses often reaching deep into the material with relatively small spots on the surface [Alfonsson et al., 2012; Cantor et al. 2000]. The conditions that are conducive to its occurrence include: moisture (or condensation) and oxygen, as well as the presence in the chloride environment. Pits arise as a result of initiating the anodic reaction through activating ions and cathodic reaction in the presence of oxidizing agents. The bottom of the pitting is an anode and the dissolution of the metal takes place there. The pitting environment is a cathode and oxygen reduction takes place there. The rate of dissolution of the metal in the anode is very high, as a consequence of which deep perforation and even penetration of thin-walled elements, without a greater loss of metal outside the attacked place occurs in a very short time. Pipe corrosion threatens by all pressure flow elements of pipelines, especially during water stops in pipelines.

\section{Degradation mechanism of installation in the water treatment station}

Among the degradation processes of pipeline elements, in addition to the combination of the phenomena described above, creep associated with plastic deformation as a result of elevated temperature and almost constant stress and frequent pressure change play a dominant role in degradation processes [Suslov, 2001, Cutler, 2003]. The result of this process is permanent deformation of the pipeline element causing irreparable internal damage in the form of voids, macro- and microcracks. The elements of pipelines that operate without appropriate supports and fastenings for the destruction process are significantly affected by fatigue, characterized by stresses causing the yield point to be exceeded; resulting in the destruction of material; in this case, the frequency of cyclic loads is low. Fatigue damages cause a discontinuity of the trans- and intercrystalline structure in the form of a network of cracks and developing main cracks. When the aggressive agent and external or internal mechanical stresses 
act simultaneously, stress corrosion occurs. Internal stresses can be caused by bending, welding or assembly of additional elements. This type of corrosion occurs in critical elements, i.e.: pipeline connection points, dosing points, assembly points of the measuring apparatus.

Another type of corrosion, encountered in sanitary installations is intercrystalline corrosion. It propagates along grains and proceeds at a relatively high speed, to a considerable depth [Cantor et al. 2000], decreasing the durability and ductility of the metal. It is related to the phenomenon involving formation of chromium carbides at the grain boundaries and with the impoverishment of the border areas of grains into chromium. This results in an aggressive corrosive environment or "hatching" individual grains from the steel surface, thereby reducing the thickness of the walls, or violating the coherence between particular grains without visible external signs, [5] Cutler, 2003. It results not only from the intergranular corrosion in the metal itself, but mainly in its plastic or mechanical treatment aimed at giving the material a certain specialized shape. Then, the gradual disappearance of the passive film occurs in the gaps in which the film cannot regenerate due to impeded aeration and inhibited oxygen supply. It forms in the gaps and construction cavities, under seals, heads of bolts and rivets, under sediments and scale, and in all kinds of cracks. The type of material destruction occurring in pipelines is erosion (Fig. 1).
Erosive destruction of the material is caused by the dynamic interaction of solid particles on the solid surface [Alfonsson et al., 2012]. In the process of erosion, the size of the destruction depends, to a large extent, on the nature of the carrier's motion and its speed, on the shape and size of the particles, on the temperature, the environment and chemical composition and the properties of eroded metal, i.e. hardness, abrasion resistance, ductility structure. The type of destruction depends on the angle of impact of the destructive particles on the surface. The maximum metal loss corresponds to $40^{\circ}$, regardless of the speed of the jet. When tangentially attacking a destroyed surface, it is destroyed by slip - destructive particles act on the material by sliding or rolling on it. The erosion can be caused by the turbidity of the raw water and the bed particles emitted during the flushing of the filters during hydraulic or pneumatic transport [Little et al. 2006]. The hydraulic fitting installed on the pipelines but also the places where the pipeline route changes, i.e., tees, knees and reductions, are the most exposed to the erosive impact of these elements. The erosive destruction is often a secondary effect, for example, associated with a damaged drainage in the riverbed.

\section{Corrosion hazard resulting from the use of chlorine in water treatment station}

In water treatment stations, disinfecting processes are carried out to to eliminate the bacteria

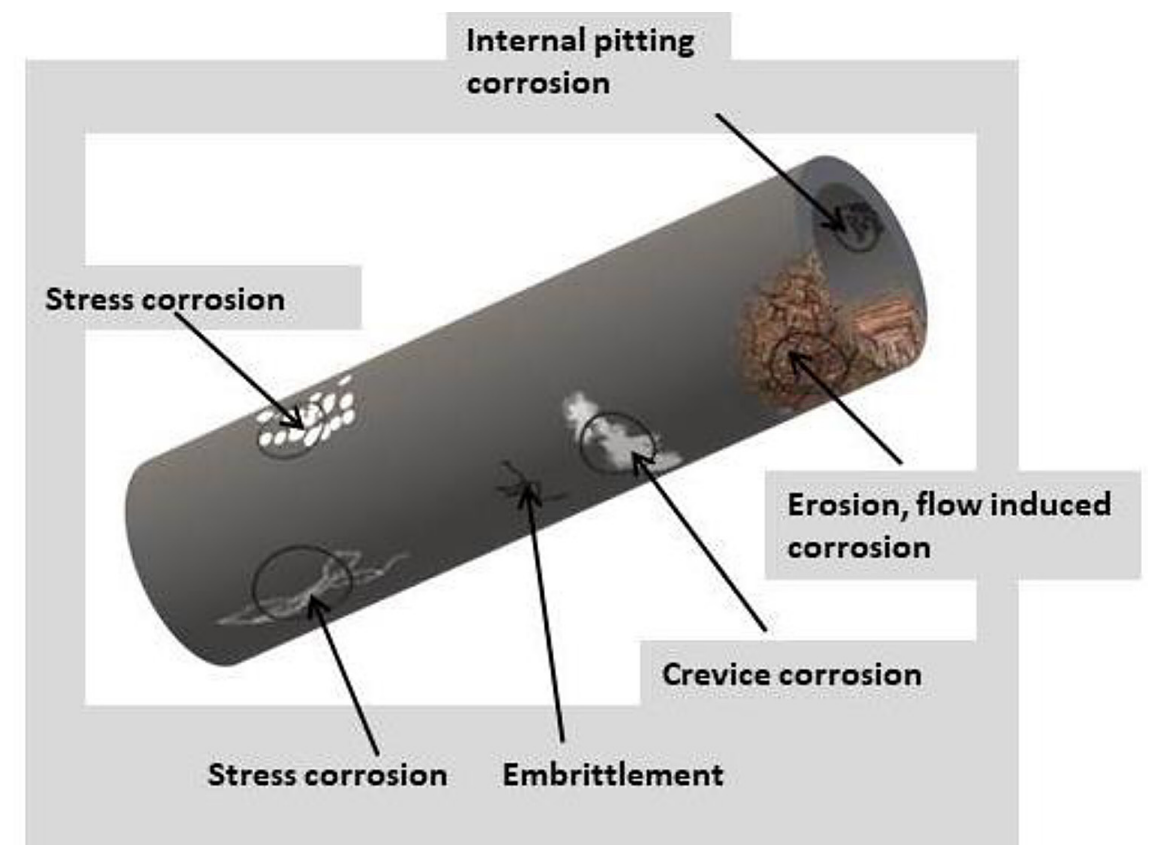

Fig. 1. Types of corrosion damage occurring in water installations 
and other microorganisms present in the water and to ensure microbiological water purity in the distribution network. Chlorination has a disinfecting role and serves to destroy the bacteria and other microorganisms present in the water and to provide microbiological water purity in the distribution network [GE Power \& Water., 1997-2012]. The process should be carried out so that the disinfectant remains in the water, protecting it from secondary infection in the distribution network. The chlorine demand (parameter determining the purity of water) is the difference between the amount added to water and the amount of free chlorine remaining after a certain time. Nominally, it is the smallest amount of chlorine free $\mathrm{Cl} 2 \mathrm{mg}$ added to $1 \mathrm{dm}^{3}$ of water at $20^{\circ} \mathrm{C}$, which gives $0.1 \mathrm{mg} / \mathrm{dm}^{3}$ of residual chlorine after 30 minutes of contact with water. The chlorine should be added to the water in such an amount that after covering the demand, the remaining free chlorine after a 30 -minute contact with water was $0.1 \mathrm{mg} / \mathrm{dm}^{3}$ of water. According to Hilbert et al. (2010), 304L steel (1.4307) can be used for free chlorine content up to $2 \mathrm{ppm}\left(2 \mathrm{mg} / \mathrm{dm}^{3}\right)$, while 316L steel (1.4404) - for $5 \mathrm{ppm}$ in raw water.

The raw water in the water treatment plant has a $\mathrm{pH}$ of about 7.5. After introducing chlorine gas, the $\mathrm{pH}$ stays within the range of 7.3-7.8. Both the chlorine content and $\mathrm{pH}$ are within the limits adopted for drinking water. Normally accepted $\mathrm{pH}$ of drinking water ranges from 6 to 8.5 . The $\mathrm{pH}$ fluctuations usually do not affect the operation of stainless steels, although local low values, for example in the gaps, are an indicator of the increased corrosion rate. Specialists believe that it is necessary to maintain a chlorine concentration of $0.5 \mathrm{mg} / \mathrm{dm}^{3}$ to effectively act on microorganisms.

In pure water, chlorine reacts with water and immediately hydrolyses to chlorine (I) $(\mathrm{HOCl})$ and hydrochloric acid $(\mathrm{HCl})$ according to equation 1 [Cutler, 2003]:

$$
\mathrm{Cl}_{2}+\mathrm{H}_{2} \mathrm{O} \rightarrow \mathrm{HOCl}+\mathrm{HCl}
$$

As a result of chlorination, the $\mathrm{pH}$ decreases and metal chlorides are formed. Between $\mathrm{pH} 6.5$ and 8.5 , the hydrolysis reaction proceeds within a few seconds and is irreversible. Chlorine acid (I) is a weak acid and partially dissociates to form a hydrogen cation and hypochlorite anion, according to equation 2 :

$$
\mathrm{HOCl} \rightarrow \mathrm{H}^{+}+\mathrm{OCl}^{-}
$$

Chlorine in the form of $\mathrm{HOCl}$ and $\mathrm{OCl}-$ known as free chlorine, has a strong bactericidal effect, similar to the atomic oxygen emitted by chloric acid decomposition, equation 3:

$$
\mathrm{HOCl} \rightarrow \mathrm{HCl}+\mathrm{O}
$$

The resistace of stainless steel to pitting or crevice corrosion depends on the concentration of chlorides in water [Moore, 2001; Borenstein, 1994; Suban et al. 2010]. Installations in networks are usually made of 1.4301 (304), 1.4307 (304L), and 1.4404 (316L) steel types. These steels usually do not cause any corrosion problems if the chloride content is low (see Table 1). Stainless steels are considered to be a useful construction material for drinking water pipelines up to a chloride concentration of $200 \mathrm{ppm}$, while the steels of 316 grade, up to a concentration of around $1000 \mathrm{ppm}$. At higher chloride concentrations, the risk of local pitting corrosion (or fissure corrosion) increases, especially if welds do not have full penetration. Pitting and crevice corrosion sometimes occur in the water containing a small concentration of chlorides if the chlorides promote microbial corrosion. $316 \mathrm{~L}$ steel with better corrosion resistance is used when deposits and higher concentrations of chlorine are present. These stainless steels are stable if the clean water flow rate is 0.5 to $0.6 \mathrm{~m} \mathrm{~s}^{-1}$ [Suban et al. 2010]. Such a flow or greater is desirable, because then there are no conditions for the formation of sediments, biofilms and the development of microbial corrosion. For raw water, a flow rate of $1 \mathrm{~m} \mathrm{~s}^{-1}$ or $1.5 \mathrm{~m} \mathrm{~s}^{-1}$ is effective to limit the bacterial growth. The 304 grade steel is used for the drinking water containing $50 \mathrm{mg} \mathrm{dm}^{-3}$ chlorides [Hilbert et al. 2009, Tuhtill et al. 1998], 316 grade steel in the water containing up to $250 \mathrm{mg} \mathrm{dm}^{-3}$ chlorides

Table 1. Resistance of stainless steels in water depending on the concentration of chlorides

\begin{tabular}{|l|l|}
\hline \multicolumn{1}{|c|}{ Chloride content } & \multicolumn{1}{c|}{ Stainless steel } \\
\hline$<200 \mathrm{ppm}$ & $1.4301(304), 1.4307(304 \mathrm{~L}), 1.4404(316 \mathrm{~L})$ \\
\hline $200-1000 \mathrm{ppm}$ & $1.4404(316 \mathrm{~L}),($ duplex 2205) \\
\hline $1000-3600 \mathrm{ppm}$ & 1.4462 (duplex 2205), super duplex, superaustenitic 6\% Mo \\
\hline$>3600 \mathrm{ppm}$ i woda morska & $6 \%$ Mo superaustenitic, super duplex \\
\hline
\end{tabular}

[Cutler 2003, Alfonsson et al. 2012] 
[Borenstein, 2002]. There is no doubt that the chloride content is the most important indicator of steel selection, due to the pitting and crevice corrosion, with the mechanism of both types of corrosion being very similar. Table 1 presents types of stainless steels showing durability for specific limits of chlorides concentration in water at ambient temperatures, if there is no microbiological corrosion [Little et al. 2007, Little et al. 2012, Mathiesen et al. 2008].

\section{Risk of microbial corrosion}

Natural water taken from deep wells contains various types of microorganisms that form biofilms on metals and accelerate the corrosion of stainless steels. Chlorination destroys microorganisms; therefore, it is to prevent microbial corrosion. The water pipes made of 304 and 316 grade steel may undergo bacterial corrosion if the water flows slowly or when there is no flow. Many factors cause the conditions under which metal alloys undergo microbial corrosion [Mathiesen 2008, Kobrin, 1998]. These include, first of all, the water flow rate and the surface roughness of the pipelines. Under normal flow conditions, bacteria do not attack smooth stainless steel. In stagnant water, the colonies of bacteria form local clusters and develop quickly, especially in the area of welds, where welding discolorations have not been removed. If there is insufficient flow in the water, there are conditions for the formation of a biofilm containing microorganisms on the surface of the steel, an aggressive environment for stainless steels, differing from the water in $\mathrm{pH}$, oxygen, organic and inorganic substances. Under microfossil corrosion, microbiological corrosion takes place at high velocities in the biofilm, because there is no oxygen supply and no sufficient water flow. Under the conditions of limited aeration, the amount of anaerobic bacteria that reduce sulfate to sulphides increases. Chlorides and sulfides react with the stainless steel substrate creating pitting in the existing micro-grids [Moreno et al. 2011]. The metabolism products formed in biofilms (inorganic and organic acids, sulfides, hydrogen sulphide, $\mathrm{CO}_{2}$ and others) cause a rapid pitting corrosion of stainless steel leading to perforation. Corrosion rate at the border of the biofilm is 100 times greater than that of a corrosive reaction under normal conditions. Most metal alloys, except for titanium, are strongly attacked [Suban et al. 2010]. In the case of stainless steels, corrosive bacteria include: Gallionella, Sphaerotilus, Pseudomonas, Desulphovibrio, Desulphotomaculum [Little et al. 2011]. Bacteria act under sediments of metal oxides and hydroxides in biovarials. Bacteria are adsorbed on metal, where they quickly reproduce and form an organic biofilm. In the outer part of the biofilm, they consume oxygen completely in the oxidation of soluble metal ions to form insoluble oxides and hydroxides, which accumulate as sediments and coatings of bacterial clusters. Very small anodes are formed in which a very fast corrosion process occurs with the participation of migrating chlorides into the pits.

\section{Effect of chemical and microbiological synergy of corrosion of stainless steel pipelines}

Microbial corrosion occurs in drinking water distribution systems in the areas where the level of residual chlorine, even in short periods of time, falls below the level required for the destruction of corrosive microorganisms. According to [Cantor et al. 2000], chlorine should be introduced into the water in an amount sufficient to obtain a concentration of $25 \mathrm{mg} \mathrm{dm}-3$, and after 12 hours, check that the concentration did not drop below $15 \mathrm{mg} \mathrm{dm}-3$. If the concentration is smaller, the disinfection process should be repeated. A high chlorine concentration of approx. $25 \mathrm{ppm}$ for disinfection purposes can only be used for 24 hours without adversely affecting stainless steel, after which chlorine must be thoroughly rinsed [Operational Guidelines and Code of Practice for Stainless Steel Products in Water Supply, 2002]. The microbial corrosion takes place particularly intensively under stagnant water conditions, in the presence of thick dark layers of metal oxides formed during welding if the oxygen content in the inert gas is too high. Corrosive bacteria usually form colonies in the area of welds.

Iron and manganese hydroxides precipitate as a result of steel oxidation. This process intensifies the presence of Gallionellia bacteria, provoking the synergy effect [Little et al. 2011, Little et al. 2012, Mathiesen et al. 2008]. Under aerobic conditions, yellow or red-brown iron compounds such as hematite $\mathrm{Fe}_{2} \mathrm{O}_{3}$ lepidokrokit y-FeOOH and $\alpha-\mathrm{FeOOH}$ goitite and manganese oxides like $\mathrm{Mn}_{3} \mathrm{O}_{4}$ are formed in the biofilm. It is difficult to rule out the formation of black $\mathrm{Mn}_{2} \mathrm{O}_{3}$ oxide or gray-black $\mathrm{MnO}_{2}$ as a result of the action of metal oxidizing bacteria, as shown schematically in Figure 2. In pits or their vicinity in the anaerobic 
environment, reduced forms of iron and manganese can prevail like black wustite and magnetite $\mathrm{FeO}$ and $\mathrm{Fe}_{3} \mathrm{O}_{4}$, or FeS [Little et al. 2006], which accelerates corrosion and possibly formation of $\mathrm{Mn}_{3} \mathrm{O}_{4}$, which can also be black.

Removal of raw water from deep wells, in which there are larger amounts of bacteria, fungi, organic substances, or sulphides, is essential to eliminate microbial corrosion. Maintaining a higher dose of chlorine should prevent the growth and activity of corrosive bacteria [Borenstein 1994, Jack, 2002].

Figure 3 shows the effect of microbiological and chemical factors, particularly chlorides (black deposits of steel oxidation products) in good-quality welds of a 316L steel tank for drinking water at a chloride content of $56 \mathrm{mg} \mathrm{dm}^{-3}$, after 2 years of downtime, which indicates a corrosion rate of about $2 \mathrm{~mm} \mathrm{month}{ }^{-1}$.

\section{CONCLUSIONS}

The direct causes of pipes corrosion include the presence of microorganisms in raw water, the parameters of technological water treatment processes and the performance of pipelines. Technological pipelines are often exploited under complex conditions, in which corrosion, erosion and plastic deformation occur jointly. This results in the disappearance of the protective action of oxides and, as a result, accelerates the destruction of the material.

The local corrosion and perforations of the installation elements from the water side are subjected to three pipeline assemblies in which the water is not in continuous flow:

- rinsing water and air pipes directed to filters,

- water pipes after rinsing,

- treated water collector from pump tanks.

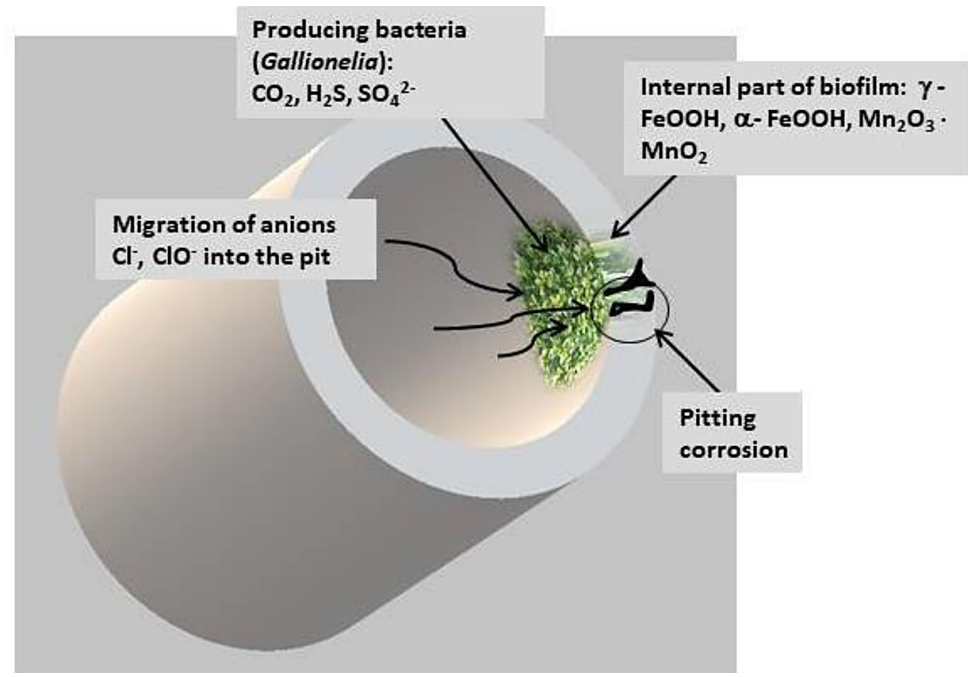

Fig. 2. Synergic effect of chemical corrosion and bacteria in water installation

a)

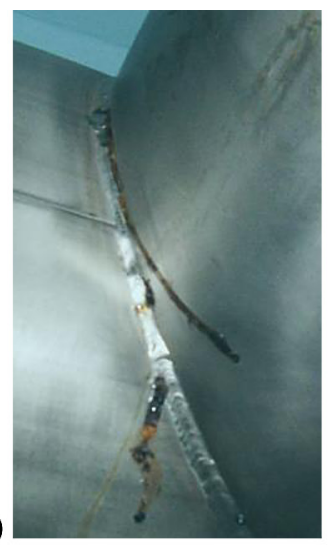

b)

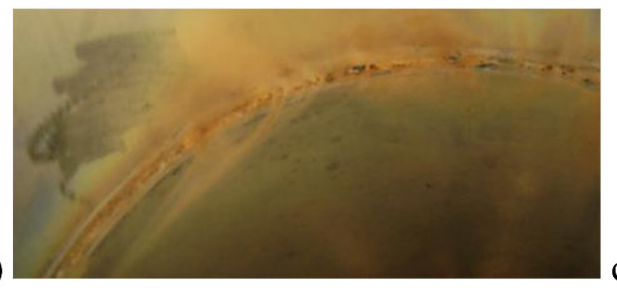

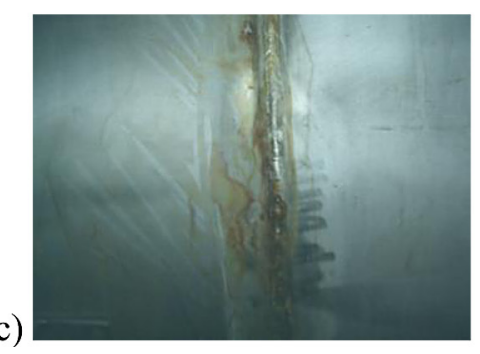

Fig. 3. a) Black-brown leakage of corrosion products from the treated water pipeline, b) Black pitting in the ridge of the weld and brown rust in the pipe cut from the pipeline of rinsing water operated for about 1.5 years, c) water collector treated for pumps with perforation of $4 \mathrm{~mm}$ thick wall after a period of about 2 years of use with black discoloration of corrosion products during perforation 
In the case of wrong choice of material, leaks occur after a few months and are most often located in the places where irregular welds edges occur, which results in the oxidation of iron and manganese compounds, facilitates the formation of gaps, flow congestion and biofilm formation.

Corresponding corrosive agents are the corrosive bacteria coming from natural water and chlorides, the concentration of which increases as a result of chlorination. These corrosive agents are particularly active under oxide deposits, causing biofilm formation on the metal. Inside the biofilm, corrosive bacteria are very active and reproduce easily, causing a rapid development of pits inside which there are no conditions for flow. The rate of microbial corrosion can be 100 times higher compared to the conditions under which microorganisms are not allowed to develop.

\section{REFERENCES}

1. Alfonsson E., Mameng S.H., The Possibilities \& Limitations of Austenitic and Duplex Stainless Steels in Chlorinated Water Systems, Outokumpu Avesta Research Center, Nuclear Exchange, May 2012.

2. Avery R.E., S. Lamb, Powell C.A., Tuthill A.H., Stainless Steel for Potable Water Treatment Plants, Nickel Development Institute, NIDI Technical Series No. 10087, 1999.

3. Borenstein S.W., Microbiologically Influenced Corrosion Failure Analysis of 304L Stainless Steel, Australian Wright Metals 2002.

4. Borenstein S.W., Microbiologically Influenced Corrosion Handbook, Woodhead Publishing Ltd., Abington, Cambridge, CGI 6AH, United Kingdom, Industrial Press, Inc. NY 1994.

5. Cantor A.F., Park J.K., Vaiyavatjamai P., The Effect of Chlorine on Corrosion in Drinking Water Systems, Midwest Technology Assistance Center, University of Illinois, the Illinois State Water Survey, Report, 2000.

6. Cutler P., Stainless Steels and Drinking Water Around the World, Nickel Institute 2003.

7. GE Power \& Water. Water \& Process Technologies, Handbook of Industrial Water Treatment, Chapter 27. Chlorine and Chlorine Alternatives 1997-2012.

8. Hedrich S., Schlomann M., Johnson D.B., The Iron-Oxidizing Proteobacteria, Microbiology, 157, 6, 2011, 1551-1564.

9. Hilbert L.R., Albrechtsen H.J., Andersen A., Effect of Material and Water Quality on Disinfection and Risks of Corrosion, Eurocorr 2010.
10. Hilbert L.R., Carpen L., Moller P., Fontenay F., Mathiesen T., Unexpected Corrosion of Stainless Steel in Low Chloride Waters - Microbial Aspects, Eurocorr 2009.

11. Jack R., Biological Corrosion Failures, ASM Handbook Volume 11: Failure Analysis and Prevention, ASM International 2002.

12. Kobrin G., Microbiologically Influenced Corrosion of Stainless Steels by Water Used for Cooling and Hydrostatic Testing, NIDI Technical Series No 10085, 1998.

13. Little B.J., Lee J.S., Microbiologically Influenced Corrosion, John Wiley \& Sons, 2007.

14. Little B.J., Lee J.S., Ray R.I., Microbiologically Influenced Corrosion, Global Phenomena, Local Mechanisms, Naval Research Laboratory Stennis Space Center, USA Report No NRL/ PP/7303-10-0367, 2011.

15. Little B.J., Lee J.S., Ray R.I., Diagnosing Microbiologically Influenced Corrosion: A State-of-theArt Review, Corrosion 62(11), 2006, 1006-1017.

16. Little B.J., Lee J.S., Ray R.I., Microbiologically Influenced Corrosion, Causative Organisms and Mechanisms, Naval Research Laboratory Stennis Space Center, USA, Report No NRL/ PP/7303-11-0671, 2012.

17. Mameng S., Pettersson R., Localised Corrosion of Stainless Steels Depending on Chlorine Dosage in Chlorinated Water, ACOM Outokumpu 3, 2011.

18. Mathiesen T., Frantsen J. E., Unusual Corrosion Failures of Stainless Steel in Low Chloride Waters Corrosion, New Orleans 2008, paper No 08174.

19. Moore M., Chlorines Effect on Corrosion in Drinking Water Systems, Midwest Technology Assistance Center, National Drinking Water Clearinghouse, West Wirginia University, Summer 2001.

20. Moreno D.A., Garcia A.M., Ranninger C., Molina B., Pitting Corrosion in Austenitic Stainless Steel Water Tanks of Hotel Trains, Revista de Metalurgia, 47, 2011, 497-506.

21. Operational Guidelines and Code of Practice for Stainless Steel Products in Drinking Water Supply, British Stainless Steel Association 2002.

22. Suban M., Cvelbar R., Bundara B., The Impact of Stagnant Water on the Corrosion Processes in a Pipeline, Materiali in tehnologije (Materials and technology) 44(6), 2010, 379-383.

23. Suslov T.V., Water Disinfection A Practical Approach to Calculating Dose Values, University of California, Agriculture and Natural Resources, Publication 7256, 2001.

24. Tuthill A.H., Avery R.E., Lamb S., Effect of Chlorine on Common Materials in Fresh Water, Materials Performance 1998, 53-56. 